Linha D'Água (Online), São Paulo, v. 29, n. 1, p. 119-141, jun. 2016

\title{
O ENSINO DE GRAMÁTICA NA PRIMEIRA REPÚBLICA (1889-1930): UMA ANÁLISE DA GRAMÁTICA EXPOSITIVA, DE EDUARDO CARLOS PEREIRA
}

\author{
THE TEACHING OF GRAMMAR IN THE FIRST REPUBLIC \\ (1889-1930): AN ANALYSES OF THE GRAMÁTICA \\ EXPOSITIVA FROM EDUARDO CARLOS PEREIRA
}

Clecio Bunzen*

Universidade Federal de Pernambuco, Recife, PE, Brasil

Rejane R. Almeida de Medeiros**

Universidade Federal de São Carlos - UFSCar, São Carlos, SP, Brasil

Resumo: No ensino de língua portuguesa ministrado para o curso secundário, entre 1889 e 1930, observa-se a primazia da gramática, em relação à leitura e escrita de textos. 0 objetivo deste artigo é discutir 0 ensino de gramática para $02^{\circ}$ e $3^{\circ}$ ano do curso secundário, na Primeira República (1889-1930), a partir da análise da Gramática expositiva: curso superior, de Eduardo Carlos Pereira. A obra, tendo tido um número elevado de reedições, desde sua publicação em 1907, pode ser representativa do ensino de gramática, no período. A análise se inscreve no campo da Linguística Aplicada, estabelecendo um diálogo com outras áreas do conhecimento, como História da Educação, História das Disciplinas Escolares, História das Ideias Linguísticas, Sociolinguística e Teoria Literária. Nas duas últimas décadas do século XIX e nas três primeiras décadas do século XX, prevaleceu no ensino de gramática a gramática expositiva, recomendando uma norma única da língua e revisitando elementos da tradição ocidental de estudos gramaticais, tanto na explicação das regras como na sua exemplificação por meio de excertos extrádos da literatura, sobretudo a portuguesa.

Palavras-chave: História do ensino de língua portuguesa; Ensino de gramática; Gramática expositiva; Tradição gramatical; Literatura e gramática.

\begin{abstract}
In the Portuguese language teaching ministered for the secondary course between the years of 1889 and 1930, it is possible to observe the primacy of grammar comparing to the reading and writing of texts. The purpose of this article is to discuss the grammar teaching for the second and third years of secondary course in the First Republic (1889-1930), through the analyses of the Gramática expositiva: curso superior, from Eduardo Carlos Pereira. As the work has had a high number of editions since its first publication in 1907, it can be representative for grammar teaching in this period. The analyses belongs to the field of Applied Linguistics and establishes a dialog with other areas of knowledge such as History of Education, History of School Disciplines, History of Linguistic Ideas, Sociolinguistics and Literary Theory. In the last two decades of the 19th century, and the three first decades of the 20th century, the expositive grammar prevailed in the grammar teaching, recommending a single norm of language and revisiting elements of the occidental tradition of grammar studies in the explanation of rules, as well as in its exemplification through exerts taken from literature, mainly the Portuguese literature.
\end{abstract}

* Professor doutor da Universidade Federal de Pernambuco - UFPE, Recife, PE, Brasil; clecio.bunzen@gmail.com

* * Doutoranda em Linguística da Universidade Federal de São Carlos - UFSCar, São Carlos, SP, Brasil; rejane_almeidademedeiros@yahoo.com.br 
Linha D'Água (Online), São Paulo, v. 29, n. 1, p. 119-141, jun. 2016

Keywords: History of Portuguese Language Teaching; Grammar Teaching; Expositive Grammar; Grammar Tradition; Literature and Grammar.

\section{Introdução}

A partir de 1870, a disciplina escolar Português, ministrada no curso secundário brasileiro, passou a lidar com três eixos de ensino: gramática, leitura e escrita (cf. RAZZINI, 2010, p. 50; cf. SOARES, 2004, p. 164-165). Contudo, nos anos que correspondem à Primeira República (1889-1930), o aprendizado da gramática foi mais requerido, no ensino de língua portuguesa, do que a leitura e a escrita de textos. $\mathrm{O}$ objetivo deste artigo é discutir o ensino de gramática ministrado para o $2^{\circ}$ e $3^{\circ}$ ano ginasial do curso secundário, entre 1889 e 1930, baseando-se na análise da Gramática expositiva: curso superior, de Eduardo Carlos Pereira. Esta análise se inscreve no campo da Linguística Aplicada, e estabelece um diálogo com outras áreas do conhecimento, como História da Educação (PFROMM NETTO et al., 1974; RIBEIRO, 1992; SOUZA, 2008); História das Disciplinas Escolares (RAZZINI, 2010; SOARES, 2004); História das Ideias Linguísticas (FÁVERO e MOLINA, 2006; LEITE, 1999; 2001; 2007; MATOS e SILVA, 1989; ROBINS, 1983), Sociolinguística (FARACO, 2008; GNERRE, 1991; ILARI e BASSO, 2006) e Teoria Literária (CURTIUS, 2013; HANSEN, 1992; RAZZINI, 2000).

Primeiramente, trataremos do lugar da disciplina Português no currículo humanista do ensino secundário, buscando compreender como a disciplina adquiriu um espaço crescente no currículo, entre os anos de 1889 e 1930. Em seguida, comentaremos os indícios que apontam para a primazia da gramática no curso secundário, no período estudado, como aqueles que se apresentam nos planos de ensino do Colégio Pedro II, e no número de publicações e reedições de gramáticas brasileiras. Depois, contextualizaremos a Gramática expositiva e seu autor na produção didática brasileira das últimas décadas do século XIX e primeiras décadas do século XX. E, por fim, passaremos à análise do ensino proposto na Gramática expositiva: curso superior, investigando de que modo Eduardo Carlos Pereira tenta conciliar o "tradicional" e o "moderno" em suas descrições e prescrições das regras linguísticas; como alguns elementos da tradição ocidental de estudos gramaticais se fazem presentes na obra analisada; e como gramática e literatura se relacionam na exemplificação por meio de excertos literários do que o gramático considera como "bom uso" da língua portuguesa. 
Linha D'Água (Online), São Paulo, v. 29, n. 1, p. 119-141, jun. 2016

\section{1 lugar da disciplina Português no currículo humanista do ensino secundário}

Apesar de a escola pública primária ter sido concebida, na Primeira República (1889-1930), como educação popular de caráter utilitário, na qual se formaria o trabalhador, e ter iniciado sua expansão já na transição do século XIX para o XX ${ }^{1}$; a escola secundária permanecia assentada sobre estudos desinteressados, e voltada à formação de um pequeno grupo social. Nessa escola, os filhos de famílias da oligarquia agrária, de industriais, grandes comerciantes, profissionais liberais ou da incipiente classe média urbana preparavam-se para o ingresso nas faculdades de Direito, Medicina e Engenharia, ao passo que adquiriam uma cultura geral baseada em estudos humanistas ${ }^{2}$, que os elevava também em distinção social (SOUZA, 2008, p. 89; RIBEIRO, 1992, p. 80-83).

Durante as primeiras décadas do século XX, podiam ser encontrados dois sistemas paralelos de ensino secundário: os estudos regulares, que tinham duração de seis anos e eram realizados nos ginásios mantidos pelos governos estaduais e em alguns colégios particulares equiparados ao Colégio Pedro II; e os estudos parcelados, que, por sua vez, predominavam nos estabelecimentos particulares de ensino. A forma de acesso à $1^{\text {a }}$ série ginasial se dava, geralmente, por meio de exame de admissão, considerado, à época, como "o requisito mais importante de comprovação do conhecimento e maturidade do estudante para o ingresso no curso secundário" (SOUZA, 2008, p. 91 e 108).

Com a instauração do regime político republicano em 1889, a organização do currículo do curso regular passou por sucessivas reformas, as quais, estando sob influência positivista, objetivaram conferir ao secundário um caráter mais científico. Entretanto, como assinalam Ribeiro (1992, p. 81), Souza (2008, p. 98-100 e 113) e Azevedo (2010, p. 673), as disputas entre as disciplinas científicas e clássicas acabaram por tornar o ensino secundário mais enciclopédico do que científico. Pela reforma de 1901, embora as disciplinas científicas, como Matemática, Mecânica, Astronomia, Física, Química e História Natural, tivessem recebido um destaque

\footnotetext{
1 Embora a escola primária tenha se expandido consideravelmente durante a Primeira República, essa expansão ainda não era suficiente para atender a maioria das crianças em idade escolar (cf. SOUZA, 2008, p. 47-48).

2 O currículo clássico humanista centrava suas escolhas na formação de uma pessoa racional e ilustrada, cujo modelo curricular tinha como objetivo "introduzir os estudantes ao repertório das grandes obras literárias e artísticas das heranças clássicas grega e latina, incluindo o domínio das respectivas línguas. Supostamente, essas obras encarnavam as melhores realizações e os mais altos ideais do espírito humano. O conhecimento dessas obras não estava separado do objetivo de formar um homem (sim, o macho da espécie) que encarnasse esses ideais". (SILVA, 2015, p. 26).
} 
Linha D'Água (Online), São Paulo, v. 29, n. 1, p. 119-141, jun. 2016

um pouco maior no currículo, com elevação da carga horária; o que se observava era a primazia dos estudos humanistas, com a permanência das disciplinas Português, Francês, Inglês e Latim nos primeiros anos do curso ${ }^{3}$. Já pela reforma de 1925, os alunos deveriam estudar vinte e cinco disciplinas diferentes, sendo duas facultativas (Alemão e Italiano); de modo que, sob o enciclopedismo, tentava-se conciliar a tradição dos estudos humanistas com a modernidade dos científicos.

Para Souza (2008, p. 101), as transformações mais significativas ocorridas nos currículos do ensino secundário, ao longo da Primeira República, estiveram relacionadas ao espaço crescente que as disciplinas de conteúdos de referência nacional, como Português, Literatura, História e Geografia, adquiriram nos planos de ensino, em virtude do nacionalismo da época. Em se tratando de Português, além da obrigatoriedade nos exames preparatórios (testes exigidos para o ingresso nas faculdades), os quais passaram a exigir a disciplina a partir de 1869 , contribuiu para a sua afirmação nos programas a correspondência estabelecida no período, pelos intelectuais brasileiros, entre língua materna e identidade nacional (SOUZA, 2008, p. 102; cf. RAZZINI, 2010, p. 48).

Entre 1890 e 1930, o ensino de português ocupou um lugar expressivo nos currículos do secundário, como demonstram os programas do Colégio Pedro II, instituição que servia de modelo para as demais escolas secundárias públicas e privadas do país. Na maioria das vezes, as aulas de língua portuguesa eram ministradas nos primeiros três ou quatro anos do ensino secundário. $O$ fato de as aulas distribuírem-se nos primeiros anos do curso atesta a importância da disciplina; visto que grande parte dos estudantes frequentava apenas esses anos, objetivando cumprir os requisitos dos exames preparatórios.

\section{A primazia da gramática no ensino de português}

Os planos de ensino de Português do Colégio Pedro II, que estiveram em vigor no final do século XIX e nas três primeiras décadas do XX, previam o estudo da gramática expositiva e da gramática histórica; a leitura e recitação de trechos de prosadores e poetas brasileiros e portugueses; bem como exercícios de redação e

\footnotetext{
3 Conforme Souza (2008, p. 100), essa distribuição das disciplinas científicas no final do curso evidencia o pouco alcance da educação científica no âmbito do ensino secundário, já que boa parte dos alunos abandonava os colégios antes de completar o curso, deixando de frequentar as disciplinas que não eram exigidas nos exames preparatórios, requisito para 0 ingresso nas faculdades.
} 
Linha D'Água (Online), São Paulo, v. 29, n. 1, p. 119-141, jun. 2016

composição ${ }^{4}$. Embora a leitura e a escrita aparecessem contempladas nos programas, a ênfase dada nesses documentos à gramática expositiva, ou gramática normativa, conforme denominação atual, é um indicativo de que, no período mencionado, o ensino de português estava mais voltado ao aprendizado da gramática normativa da língua portuguesa. Assim, o programa de 1893, por exemplo, trazia uma extensa lista com quatorze temas da gramática expositiva a serem estudados no $1^{\circ}$ ano, e dezoito, no $2^{\circ}$, os quais deveriam ser revisados no $4^{\circ}$ e no $5^{\circ}$ ano. $\mathrm{O} 3^{\circ}$ ano seria dedicado à gramática histórica. Seguindo a mesma tendência, o currículo de 1926 arrolava uma grande quantidade de conteúdos gramaticais, que chegava a somar quarenta itens no $1^{\circ}$ ano, vinte e três no $2^{\circ}$, e novamente vinte e três no $3^{\circ}$ ano.

Essa primazia da gramática expositiva em relação à leitura e escrita no ensino de língua portuguesa foi igualmente observada por Razzini (2010). Ao estudar a trajetória da disciplina Português no Colégio Pedro II, a partir da análise da legislação do nível secundário, dos planos de ensino elaborados e dos livros escolares adotados no estabelecimento escolar, a pesquisadora conclui que, entre 1890 e 1930, além da importância que a gramática adquiriu nos planos de ensino, confirmam a sua preeminência a adoção de um número elevado de gramáticas, quando comparado ao de antologias, livros que compunham o material escolar dos alunos à época, e que, muitas vezes, serviam de orientação ao professor (RAZZINI, 2010, p. 53).

O destaque conferido à gramática no ensino de português, durante a Primeira República, pode ser evidenciado ainda pela publicação e reedição de inúmeras gramáticas brasileiras. Embora várias seletas tivessem sido produzidas no Brasil, no fim do século XIX e início do XX, apenas três registraram um número expressivo de edições até 1930, segundo os apontamentos de Pfromm Netto et al. (1974, p. 203): a Antologia nacional, de Fausto Barreto e Carlos de Laet, de 1895, a qual teve dezenas de edições; Céu, terra e mar, de Antonio Mariano Alberto, cuja quarta edição data de 1920; e a Seleta clássica, de João Ribeiro, lançada em 1905, com quatro edições publicadas até 1931. Por outro lado, as gramáticas se apresentaram em número maior, provavelmente devido a sua grande aceitação e usos nas escolas. Entre as que foram publicadas nas últimas décadas do século XIX, e que continuaram a ser editadas nas primeiras décadas do XX, encontram-se, por exemplo, a Gramática portuguesa, curso elementar ( $1^{\circ}$ ano), médio ( $2^{\circ}$ ano), e superior ( $3^{\circ}$ ano), de João Ribeiro, que, sendo lançada entre 1886 e 1887, chegou a atingir em 1941, respectivamente, 97, 39 e 21 edições; a Gramática da lingua portuguesa, de Pacheco da Silva Júnior e Lameira de Andrade, que, desde 1887 até 1913, teve

4 Referimo-nos aos planos de ensino de Português do Colégio Pedro II, elaborados entre 1892 e 1929, os quais foram compilados por Razzini (2000, p. $314-338$ ). 
Linha D'Água (Online), São Paulo, v. 29, n. 1, p. 119-141, jun. 2016

quatro edições publicadas; a Gramática portuguesa, de Alfredo Gomes, também de 1887, cuja 19a edição apareceu em 1924; e a Gramática descritiva, de Maximino Maciel, que, saída igualmente em 1887, contava com sua 8a edição em 1922. Já dentre as gramáticas lançadas no intervalo dos anos de 1900 e 1930, teve grande circulação nas escolas a Gramática expositiva primária, de Carlos Góis, de 1919, com nove edições publicadas até 1951 (cf. PFROMM NETTO et al., 1974, p. 198-199); entretanto, foi a Gramática expositiva: curso superior, de Eduardo Carlos Pereira, cuja análise se procederá em seguida, que mais esteve presente nos bancos escolares. Tendo surgido em 1907, e com 114 edições até 1958, a obra se constituiu como uma referência no estudo da língua portuguesa (cf. MOLINA, 2004, p. 247250; PFROMM NETTO et al., 1974, p. 200).

\section{A Gramática expositiva, de Eduardo Carlos Pereira}

Pfromm Netto et al. (1974, p. 200), ao recensear os livros escolares produzidos na primeira metade do século XX, conclui que "o acontecimento mais importante das primeiras décadas do século atual [século XX], na história dos livros didáticos de português, foi o aparecimento das gramáticas de Eduardo Carlos Pereira”. A Gramática expositiva foi publicada, pela primeira vez, em 1907, pela editora Weiszflog Irmãos e Companhia, tendo como propósito atender ao programa oficial para os três primeiros anos do ginásio (MOLINA, 2004, p. 239). Desde 1907 até 1958, a obra teve 114 (cento e catorze) edições; e, segundo dados levantados por Molina (2004, p. 247-250), a partir da 30a edição, realizada pela Companhia Editora Nacional em 1932, teve uma tiragem de 460.000 (quatrocentos e sessenta mil) exemplares.

Ainda em 1907, Eduardo Carlos Pereira decide elaborar uma gramática mais simplificada, extraída da Gramática expositiva e voltada ao $1^{\circ}$ ano, a qual denomina de Gramática expositiva: curso elementar. A partir da 2a edição, realizada em 1909, sob a responsabilidade da Duprat \& Companhia, a obra original restringe-se ao $2^{\circ}$ e $3^{\circ}$ ano, e recebe a designação de Gramática expositiva: curso superior ${ }^{5}$ (MOLINA, 2004, p. 241; PEREIRA, Prólogo da 2a edição [1909], 1925). De acordo com indicações apresentadas em um dos textos introdutórios da Gramática expositiva: curso superior, denominado de "Explanações", no $2^{\circ}$ ano deveriam ser ensinadas a fonologia, a

5 A $17^{a}$ edição da Gramática expositiva: curso superior, objeto deste estudo, foi publicada em 1925, pela Companhia Gráfico-Editora Monteiro Lobato. Ela foi a última a ser realizada pela Companhia Gráfico-Editora Monteiro Lobato. Após a falência da empresa, os direitos da obra passaram a pertencer à Companhia Editora Nacional (MOLINA, 2004, p. 247). 
Linha D'Água (Online), São Paulo, v. 29, n. 1, p. 119-141, jun. 2016

morfologia e a etimologia; enquanto que no $3^{\circ}$ ano se faria uma revisão dos conteúdos do ano anterior, e se estudaria a sintaxe (PEREIRA, Explanações, 1925).

A experiência pedagógica de Eduardo Carlos Pereira, como afirma o próprio autor no "Prólogo da $1^{\text {a }}$ edição" da obra, motivou a produção da Gramática expositiva: "A boa regência de nossa cadeira de português no Ginásio Oficial da cidade de São Paulo nos levou ao presente trabalho" (PEREIRA, Prólogo da 1a edição [1907], 1925). Eduardo Carlos Pereira (1855-1923), nascido em Caldas, Minas Gerais, tinha aprendido as primeiras letras com o seu irmão mais velho, frequentado escola na mesma cidade, onde estudou latim e francês e, já instalado em São Paulo, cursou o Colégio Ipiranga de Araraquara, e seguiu os estudos superiores na Academia de Direito de São Paulo. Durante sua carreira no magistério, lecionou Latim e Português no Colégio Culto à Ciência, em Campinas, na Escola Americana (Mackenzie) e no Ginásio Oficial de São Paulo, ambas localizadas na capital paulista (MOLINA, 2004, p. 213-215; FACCINA e CASAGRANDE, 2006, p. 83).

O gramático e professor faz parte de uma geração de autores de livros escolares que também exerciam a docência. De acordo com Bittencourt (2004, p. 483), a partir dos anos de 1870 e 1880, com a expansão do ensino elementar público, houve uma valorização dos autores didáticos, que possuíssem "experiências pedagógicas provenientes de cursos primários, secundários ou de escolas normais voltadas para a formação de professores"; o que despertou também o interesse das editoras em publicar suas obras, tendo em vista as preferências de seu público consumidor. A partir de 1887, quando o programa de português para os exames preparatórios do Colégio Pedro II foi reestruturado por Fausto Barreto (1852-1915), houve um aumento na produção de gramáticas escolares brasileiras produzidas por docentes. Nessa década e na seguinte, estando de acordo com o programa proposto por Barreto, publicaram-se obras de grande aceitação no cenário educacional, como a Gramática da lingua portuguesa, de Pacheco da Silva Júnior e Lameira de Andrade, a Gramática analítica, de Maximino Maciel, a Gramática portuguesa, de Alfredo Gomes, e a Gramática portuguesa, de João Ribeiro (RAZZINI, 2000, p. 83-84; MOLINA, 2004, p. 66).

\section{0 ensino proposto na Gramática expositiva: curso superior: equilíbrio entre o tradicional e o moderno?}

No "Prólogo da 1a edição", Eduardo Carlos Pereira descreve sua gramática como sendo o resultado de um "caminho próprio" que, como professor de português, procurou traçar, equilibrando duas correntes de estudos gramaticais: "a corrente 
Linha D'Água (Online), São Paulo, v. 29, n. 1, p. 119-141, jun. 2016

moderna”, representada pela Gramática Histórica, e "a corrente tradicional”, calcada nos estudos greco-latinos e na Gramática Geral/Filosófica:

A orientação que seguimos, expo-la-emos em poucas palavras.

Em primeiro lugar, procuramos a resultante das duas correntes: - da corrente moderna, que dá ênfase ao elemento histórico da língua, e da corrente tradicional, que se preocupa com o elemento lógico na expressão do pensamento. Há verdade nas duas correntes: o erro está no exclusivismo de uma e de outra, ou, melhor, na confusão de ambas (PEREIRA, Prólogo da 1ª edição [1907], 1925).

O método histórico-comparativo foi introduzido no Brasil por Júlio Ribeiro (1845-1890) em 1881, quando se publicou, pela primeira vez, a sua Gramática portuguesa. Apesar de a obra de Júlio Ribeiro não ter sido uma das mais utilizadas nas escolas, esta teve um papel preponderante na gramatização brasileira, e no ensino de língua portuguesa ministrado no final do século XIX e início do século XX. Além de ser a primeira gramática a empregar o método histórico-comparativo no Brasil, inaugurando, assim, o periodo cientifico de nossa gramaticografia ${ }^{6}$, o compêndio, que fora também adotado no Colégio Pedro II em 1882, serviu de base para a delimitação dos programas de exames dessa instituição, os quais, por sua vez, norteariam as gramáticas mais importantes do século XIX, e constituiriam, inclusive, "germe para muitas das que atravessaram o século XX" (FÁVERO e MOLINA, 2006, p. 127; MOLINA, 2004, p. 66-68). Eduardo Carlos Pereira, no "Prólogo da 1a edição"(1907) de sua Gramática expositiva:curso superior, chegou inclusive a admitir a importância de Júlio Ribeiro na reorientação do ensino de gramática (cf. PEREIRA, Prólogo da 1a edição [1907], 1925).

De acordo com Fávero e Molina (2006, p. 129), o próprio Júlio Ribeiro, na Gramática portuguesa (1881), tenta conciliar "a nova corrente", isto é, a Gramática Histórica, com "a escola tradicional”, calcada nos estudos greco-latinos e na Gramática Geral. Embora o autor faça uso do método histórico-comparativo para estudos do português, não chega a negar completamente as antigas teorias; visto que, se o propósito do evolucionismo é apenas explicar os fatos da linguagem, este tenderia a não valorizar uma norma única da língua, e consequentemente o seu

$6 \quad$ Elia (1975, p. 117-121) divide os estudos filológicos no Brasil em dois períodos: o vernaculista, de 1820 a 1880, e o científico, de 1880 a 1960. Segundo o autor, no período científico, "as forças de renovação prevalecem sobre as de conservação (...)". "Nessa fase, o sentido renovador volta-se ainda para as explanações gramaticais, procurando imprimir à disciplina do idioma fundamento mais consentâneo com o progresso dos estudos linguísticos" (p. 121). 
Linha D'Água (Online), São Paulo, v. 29, n. 1, p. 119-141, jun. 2016

ensino (FÁVERO e MOLINA, 2006, p. 129). Essa tentativa de conciliação aparece também na Gramática expositiva: curso superior, quando, em sua obra, Eduardo Carlos Pereira elege a "gramática expositiva", ou normativa, para o ensino da "língua nacional", e reserva as explicações históricas do fenômeno linguístico às breves "notas" e "observações":

Ninguém contesta, certamente, que os fatos atuais da língua têm sua explicação racional nos antecedentes históricos da mesma língua. É na fonologia, na morfologia ou sintaxe históricas que encontramos a razão de ser das regras atuais da gramática expositiva sobre a pronúncia, sobre a forma dos vocábulos, ou sobre os processos sintáticos. Daí não se segue, porém, que o estudo da gramática histórica deva anteceder ou mesmo acompanhar o estudo da gramática expositiva. É esta, entretanto, a lamentável confusão que tem grandemente prejudicado, nestes últimos tempos, o ensino da língua nacional. Basta, para satisfazer as exigências nacionais do ensino expositivo, seguir-se a opinião criteriosa de Brachet, isto é, basta ministrar a dosagem histórica ao alcance do aluno, suficiente para a clara inteligência dos fenômenos atuais, sem que seja necessário baralhar o estudo da gramática histórica com o estudo da gramática expositiva. Obedecendo a este critério, consignamos, nas Notas e Observações rápidas explanações históricas sobre a regra expendida no texto (PEREIRA, Prólogo da 1a edição [1907], 1925, itálicos do autor/editor).

Segundo os modos que o autor nos dá a ler a sua obra, expostos no "Prólogo da $1^{\text {a }}$ edição", as regras que o aluno deveria aprender seriam aquelas da "gramática expositiva", apresentadas na parte do livro que Pereira denomina de "texto"; enquanto que as informações acerca da história da língua, escritas em tamanho de letra menor nas "notas" e "observações", serviriam apenas à compreensão dos "fenômenos atuais" da língua.

Pfromm Netto et al. (1974, p. 201), comentam que, apesar da boa aceitação que a Gramática expositiva: curso superior adquiriu junto ao professorado brasileiro, algumas críticas colocaram em dúvida "o suposto equilíbrio entre as correntes tradicional e moderna que Pereira acreditava ter logrado"; como a realizada por Silveira Bueno em 1953, que considerou que a obra tinha conseguido totalizar as preferências do Brasil porque, "apesar de aparecer em 1907, representava uma volta aos lugares comuns do ensino ginasial”. A análise do espaço reservado à gramática normativa, e à Gramática Histórica no livro de Eduardo Carlos Pereira parece corroborar as afirmações de Silveira Bueno. 
Na seção do livro escolar intitulada "Gramática e sua divisão", Eduardo Carlos Pereira define a gramática como sendo "a sistematização dos fatos da linguagem”, e em seguida, faz uma observação, na qual procura demonstrar duas concepções de gramática: a gramática como arte, sustentada entre os gregos e latinos, e na idade Média; e a gramática como ciência, surgida com a linguística moderna (ou histórica). A observação feita pelo autor tem o objetivo de, por um lado, alargar o conceito de gramática, inicialmente apresentado, abarcando essas duas correntes gramaticais, e por outro, defender a eleição da gramática como arte, ou a gramática da tradição, como objeto de ensino da Gramática expositiva: curso superior. Para o autor, o ensino de gramática deveria basear-se no "bom uso", na "arte de escrever e falar corretamente":

Obs. (...) E o exímio romanista Arsène Darmesteter, cuja autoridade está acima de qualquer contestação, escreve, na Introdução de seu Cours de Grammaire Historique de la Langue Française: "A concepção de gramática como ciência, é, podemos dizê-lo, uma ideia nova nascida com a linguística moderna. Assim entendida, é a gramática de uma língua a determinação das leis naturais, que a regem em sua evolução histórica. A gramática, acrescenta ele, pode ser considerada como arte. Deste modo a encararam os gregos e os latinos, e a Idade Média, e assim encaram os gramáticos modernos que não se prendem à escola histórica. Da antiga Roma nos veio esta definição: a gramática é a arte de escrever e falar corretamente. Existe uma boa tradição: a gramática tem o dever de a tornar conhecida e defendê-la contra qualquer alteração. É ensinando o bom uso que ela não se contenta em ser ciência, e torna-se arte (Gr. Historique, pags. 6 e 9)" (PEREIRA, 1925, p. 3, itálicos do autor/editor).

O "uso correto da língua portuguesa", recomendado pela Gramática expositiva: curso superior, caracterizaria o que Leite (1999, p. 47-48), apoiada nas definições de Neustupný (1989), tratou como sendo "purismo do idioma", o qual "consiste do discurso que se refere a processos de correção que supostamente 'purificariam' ou 'atenticariam' a linguagem". O conceito de "pureza", e, portanto o de "correto", tem como critério a seleção de um uso, que geralmente é aquele praticado pela camada de maior prestígio sociocultural e econômico de uma dada sociedade (cf. LEITE, 1999, p. 45-46).

A obra de Eduardo Carlos Pereira, apesar de empregar a gramática histórica em suas descrições, utiliza como objeto de ensino a gramática normativa, descrevendo a norma padrão vigente e preconizando "o uso correto da língua portuguesa"; dado o papel periférico que as "notas" e "observações" assumem no livro escolar. 
Linha D'Água (Online), São Paulo, v. 29, n. 1, p. 119-141, jun. 2016

\section{A tradição na Gramática expositiva: curso superior}

A Gramática expositiva: curso superior, na seção denominada "Noções preliminares", apresenta alguns conceitos, como os de linguagem e lingua. Para Eduardo Carlos Pereira, a "linguagem é a expressão do pensamento por meio de palavras"; e a "língua é um sistema natural de palavras de que servem os agrupamentos de homens para entre si comunicarem seus pensamentos" (PEREIRA, 1925, p. 1).

Ao se referir à língua como "um sistema natural de palavras", o gramático parece retomar uma antiga noção sustentada pelos filósofos gregos da "escola naturalista", do século $\mathrm{V}$ a. C., que afirmavam haver uma correspondência necessária entre as palavras e as coisas significadas (cf. LYONS, 1979, p. 4). Por outro lado, as concepções de linguagem e de língua expressas pelo autor relacionam-se também àquelas da Gramática Geral ou Filosófica, modelo teórico surgido no século XVII, voltado à especulação medieval de tradição greco-latina, que acreditava que a estrutura da língua era um produto da razão, e que as línguas, apesar de serem diferentes entre si, obedeciam a princípios lógicos universais ${ }^{7}$ (cf. LYONS, 1979, p. 17-18; WEEDWOOD, 2002, p. 100). Desta ideia adveio também a crença de que o "falar bem lógico" seria resultante do raciocínio ordenado segundo as operações estabelecidas pela Lógica (cf. MATTOS e SILVA, 1989, p. 27).

Quanto aos conteúdos abordados na Gramática expositiva: curso superior, estes se dividem em duas partes: 1) lexeologia, em que são tratadas a fonologia (abarcando fonética, prosódia e ortografia) e a morfologia (incluindo a taxeonomia e a etimologia; e 2) sintaxe, na qual são estudadas a proposição e seus membros, período gramatical, particularidades sintáticas e pontuação. Essa distribuição dos conteúdos na gramática de Eduardo Carlos Pereira em dois polos - lexeologia, de um lado, e sintaxe, de outro -, remonta à tradição greco-latina de estudos gramaticais que se delineou ainda na Antiguidade (cf. MATTOS e SILVA, 1989, p. 15).

A primeira gramática ocidental de que se tem notícia, a Arte da gramática, de Dionísio Trácio, produzida entre os séculos II e I a. C., ao se dedicar à sistematização das classes de palavras e à análise morfológica da língua grega, estabeleceu uma tradição lexicológica que, além de abarcar a fonética, distinguia as partes do discurso em oito - nome, verbo, particípio, artigo, pronome, preposição, advérbio,

A partir da publicação da Grammaire générale et raisonée, de Port Royal, em 1660, a Gramática Geral ou Filosófica teve larga influência sobre os estudos gramaticais e sobre o ensino. De acordo com Bagno (N. do T. in WEEDWOOD, 200, p. 100), "a Gramática filosófica da língua portuguesa, de Jerônimo Soares Barbosa, escrita em 1803, mas só publicada em 1822, [em Portugal], é a representante mais notável dos princípios da Grammaire générale de Port-Royal em nossa língua". 
Linha D'Água (Online), São Paulo, v. 29, n. 1, p. 119-141, jun. 2016

conjunção ${ }^{8}$ (NEVES, 2002, p. 52-53; ROBINS, 1983, p. 24; MATTOS e SILVA, 1989, p. 18). Quanto à sintaxe, esta fora introduzida nos estudos gramaticais por Apolônio Díscolo, com a elaboração, no século II d. C., da obra Da sintaxe (NEVES, 2002, p. 61-63; MATTOS e SILVA, 1989, p. 18). As gramáticas latinas que se seguiram, em sua maioria, se fizeram por decalque do modelo de descrição do grego, acrescentando em sua estrutura apenas uma parte dedicada à retórica e à estilística ${ }^{9}$ (LEITE, 2007, p. 66). É o caso, por exemplo, de uma das obras mais representativas da erudição linguística romana e que serviu de base para a educação do final da Antiguidade, da Idade Média latina e do ensino tradicional do mundo moderno ocidental, a Institutiones grammaticae, de Prisciano (século V d. C.), que retoma a doutrina grega constituída tanto pela Arte da gramática, de Dionísio Trácio, no tratamento da morfologia, como por Da sintaxe, de Apolônio Díscolo, em se tratando do estudo da sintaxe (ROBINS, 1983, p. 42-44).

A divisão das classes de palavras adotada por Eduardo Carlos Pereira, na Gramática expositiva: curso superior, aproxima-se daquela proposta pelo gramático grego Dionísio Trácio, com pequenas diferenças: incluiu-se a interjeição, a classe do nome foi separada em substantivo e adjetivo, e na categoria do adjetivo entraram o artigo e o particípio (cf. PEREIRA, 1929, p. 60). Já a distinção de frase e proposiçãa ou oração, esta é retomada da noção de sintaxe apresentada por Prisciano (século V d. C.). Conforme Mattos e Silva (1989, p. 20), a sintaxe fora definida pelo gramático latino como sendo a disposição que visa à obtenção de uma oração perfeita; designação esta que se assentava sobre princípios lógicos, nos quais os conceitos de oração perfeita/imperfeita envolviam a distinção da transitividade dos verbos. Os mesmos conceitos aparecem na gramática escolar de Pereira, quando se definem "frase" como "expressão completa ou incompleta" e "proposição ou oração" como a frase de sentido completo:

8 Os substantivos e os verbos foram, primeiramente, categorizados por Platão (429-347 a. C.) como termos de uma proposição: os substantivos eram termos que funcionavam nas frases como sujeitos de um predicado; e os verbos eram termos que expressavam a ação ou afirmavam a qualidade dos sujeitos, de modo que não se fazia distinção entre verbos e adjetivos. $A$ categorização de Platão foi conservada por Aristóteles (384-322 a. C.), que acrescentou uma terceira classe, as conjunções. Posteriormente, os gramáticos de Alexandria reuniram os substantivos e os adjetivos na classe dos nomes, definição que permaneceu até a ldade Média, e dividiram as partes do discurso em oito (LYONS, 1979, p. 11; FARACO, 2008, p. 132).

9 Foge a esta regra, de acordo com Leite $(2007$, p. 66), a gramática de Varrão (sec. I a. C., 1 16-27), "latino que retomou a Techné de Dionísio, mas a ampliou, fez uma análise crítica da doutrina linguística para, enfim, descrever a língua latina não como um decalque da grega, mas como uma apresentação de suas próprias características". 
Linha D'Água (Online), São Paulo, v. 29, n. 1, p. 119-141, jun. 2016

9. Frase, a combinação de palavras, que exprime um pensamento, é o elemento fundamental da linguagem. A frase pode ser a expressão completa ou incompleta do pensamento: a flor do jardim - é uma frase ou expressão de sentido incompleto; a flor do jardim é bela, de sentido completo. Esta última constitui o que se chama proposição ou oração.

10. Proposição é a frase de sentido completo, que contém a declaração de alguma coisa, p. ex.: O sol ilumina a terra com luz extremamente viva.

(...)

Toda a proposição deve conter dois termos essenciais - o SUJEITO e o PREDICADO, e um acessório - o COMPLEMENTO. (PEREIRA, 1925, p. 2, maiúsculas, itálicos e grifos do autor/editor).

A Gramática expositiva: curso superior, de Eduardo Carlos Pereira, tanto na organização de seus conteúdos em duas partes (lexeologia e sintaxe) como no tratamento de alguns conceitos (língua, linguagem, divisão das classes de palavras, frase e proposição) retoma a antiga tradição de estudos gramaticais estabelecida no Ocidente por Dionísio Trácio, na Arte da gramática (I-II a. C.), por Apolônio Díscolo, em Da sintaxe (II d. C.), e por Prisciano, em Institutiones grammaticae (V d. C.).

\section{0 excerto literário como exemplo de "bom uso" da língua portuguesa}

Em um dos textos introdutórios da Gramática expositiva: curso superior, intitulado "Autoridades clássicas que amplamente autorizam as teorias desta gramática", são listados nomes de vinte autores, sendo dezesseis portugueses - Alexandre Herculano (1810-1877), Antonio Feliciano de Castilho (1800-1875), José Maria Latino Coelho (1825-1891), Almeida Garret (1799-1854), Luiz Augusto Rabello da Silva (1822-1871), Camillo Castelo Branco (1825-1890), Filinto Elysio (17341819), Padre Antonio Pereira (1725-1797), Padre Manoel Bernardes (1644-1710), Frei Luiz de Souza (1555-1632), Jacintho Freire de Andrade (1597-1657), Dom Francisco Manoel de Mello (1608-1666), Sá de Menezes (1600-1664), Francisco Rodrigues Lobo (1580-1622), Luiz de Camões (1524-1580) e Gil Vicente (14651536?); três brasileiros - Gonçalves Dias (1823-1864), Odorico Mendes (17991864) e João Francisco Lisboa (1812-1863); e um nascido em Portugal e radicado no Brasil - Padre Antonio Vieira (1608-1697).

$\mathrm{Na}$ designação usada por Eduardo Carlos Pereira para se referir aos autores brasileiros e portugueses, em cujos exemplos se apoiarão as teorias de sua gramática, encontra-se a concepção greco-romana de autoria como auctoritas (autoridade). 
Linha D'Água (Online), São Paulo, v. 29, n. 1, p. 119-141, jun. 2016

Segundo o conceito, auctor (autor) é o artífice que executa sua arte por meio de uma técnica (ars) formada por regras precisas de articulação, e, assim, fornece exemplos de um uso autorizado e virtuoso, que deve ser imitado (HANSEN, 1992, p. 18-29).

As "autoridades clássicas" elencadas pelo gramático na abertura de sua obra são poetas e prosadores da literatura brasileira e portuguesa, produzida entre os séculos XV e XIX. Ao balizar suas teorias em escritores consagrados de língua portuguesa, a Gramática expositiva: curso superior retoma uma antiga tradição gramatical surgida entre os gramáticos de Alexandria, na Grécia Antiga; a qual esteve fundada no estudo dos textos dos poetas clássicos e na prescrição dos usos linguísticos desses autores.

No período em que floresceu a filosofia na Hélade, época de Platão e Aristóteles, o termo grammatikós era empregado apenas para se referir àquele que dominava o uso das letras, grámmata, que conhecia o alfabeto e sabia utilizá-lo na escrita e na leitura. O estudo do lógos, o que chamamos hoje de investigação linguística, era realizado pelos filósofos (ROBINS, 1983, p. 10). Na era helenística, entretanto, a qual compreende o tempo decorrido entre os séculos IV a. C., ocasião da morte de Alexandre, e o século I a. C., quando ocorreu a dominação romana, as reflexões sobre a linguagem passaram a ser motivadas principalmente pelo exame da literatura grega clássica (NEVES, 2002, p. 20-21). Os gramáticos de Alexandria, ao desenvolver trabalhos de estabelecimento e exegese dos textos literários antigos, julgavam as obras clássicas gregas, principalmente as de Homero; explicavam os usos linguísticos dos autores e dos textos analisados; e, com vistas à educação, fixavam padrões linguísticos a cultivar e a preservar baseados nos poetas (NEVES, 2002, p. 20-21; ROBINS, 1983, p. 9 e 13). Nesse contexto, entre os séculos II e I a. C., publicou-se a "primeira descrição explícita que se conhece da língua grega", a Arte da gramática, de Dionísio Trácio, que apresentava dupla finalidade: de um lado, estabelecia e explicava a língua dos autores clássicos, de modo a fornecer subsídios necessários ao entendimento de um dialeto que não fazia mais parte do cotidiano grego, e assim promover a apreciação adequada do texto literário; e de outro, buscava "preservar" a língua grega da "corrupção" por parte dos não letrados. (LYONS, 1979, p. 9; ROBINS, 1983, p. 24-25)

As relações entre gramática e literatura são expressas tanto na definição de gramática dada por Dionísio Trácio, em sua Arte, como na própria divisão que o conceito de gramática admitia para os gregos do período helenístico. Segundo o autor, a gramática era "o conhecimento prático do uso linguístico comum aos poetas e prosadores” (apud ROBINS, 1983, p. 24); e podia ser dividida em seis partes: 
Linha D'Água (Online), São Paulo, v. 29, n. 1, p. 119-141, jun. 2016

primeira, leitura exata (em voz alta), com a devida atenção à prosódia; segunda, explicação das expressões literárias das obras; terceira, preparo de notas sobre fraseologia e temática; quarta, descobrimento das etimologias; quinta, determinação das regularidades analógicas; sexta, crítica das composições literárias, a parte mais nobre da gramática. (ROBINS, 1983, p. 24-25).

As gramáticas latinas continuaram a colocar sua atenção na linguagem empregada nos textos da literatura clássica; fato que evidencia o prestígio da modalidade de escrita literária do latim, e o pouco interesse pelo latim falado, bem como pelo uso escrito não literário da língua, para as camadas eruditas da sociedade romana (ROBINS, 1983, p. 35). Seguindo a tradição grega, na Roma clássica, a gramática dividiu-se em duas partes: "uso correto da língua e explicação dos poetas". O termo latino litteratura circulou nas sociedades romana e medieval como equivalente de grammatica, e o "conhecedor da gramática e da poesia" era então denominado litteratus (CURTIUS, 2013, p. 78). Assim como os gregos buscaram, através do ensino gramatical, fornecer subsídios para a apreciação adequada do texto literário e preservar a língua grega usada por seus escritores clássicos; os latinos, por meio do ensino da gramática latina, objetivaram facilitar o entendimento do texto e conservar o latim literário dos autores romanos ${ }^{10}$.

É a essa tradição, que não estabelecia fronteiras precisas entre gramática e literatura, nascida na Grécia Antiga com os estudos alexandrinos, e conservada pelos latinos e medievos durante a Roma Antiga e Idade Média latina, que a Gramática expositiva: curso superior, ao apresentar excertos literários de escritores consagrados, portugueses e brasileiros, como exemplo de bom uso da língua portuguesa, parece filiar-se. No livro do gramático brasileiro, trechos extraídos da literatura, sobretudo da portuguesa, são citados como modelo de aplicação das normas gramaticais. Ao tratar do "gerúndio com valor de substantivo verbal", por exemplo, o autor utiliza sentenças e trechos de três autores portugueses, Padre Antonio Vieira (16081697), Antonio Feliciano de Castilho (1800-1875) e Camões (1524-1580):

10 A Institutiones grammaticae, de Prisciano (500 d. C.), consiste na descrição sistemática do latim da literatura clássica (ROBINS, 1983, p. 42 e 44). Ainda que sejam contempladas expressões do latim escrito pertencentes aos domínios administrativo e jurídico, visto que o manual se dirigia a estudantes para os quais o latim deixava de ser familiar (cf. BARATIN et al., 2010, p. 12); a grande maioria dos exemplos é extraída de escritores clássicos gregos e romanos, como Homero, Virgílio, Horácio, Cícero, entre outros. 
Linha D'Água (Online), São Paulo, v. 29, n. 1, p. 119-141, jun. 2016

4. Finalmente, emprega-se o gerúndio com o seu valor próprio de substantivo verbal, pelo particípio presente latino, no chamado, em latim, particípio absoluto, p. ex.: Reinando Tarquinio, veio Pitágoras para a Itália (regnante Tarquinio). - Como no caso antecedente, usurpou neste o gerúndio a função do particípio conservando, entretanto, seu valor substantivo, revelado pela anteposição da preposição em: Em reinando Tarquinio, veio Pitágoras para a Itália.

Neste emprego, como no antecedente, a preposição em é facultativa, e, entre nós, limita-se o seu uso à língua culta.

Exs.:

Frolalta, como ficava Antiocho, em te tu vindo? (C.) - Tudo quanto há na capital do Pará, tirando as terras, não vale dez mil cruzados (A. V.) - Em despontando a aurora, adeus Bootes (A. C.) - Os portugueses vendo estas memórias, dizia o Catual ao Capitão (C.).

Porém já cinco sóis eram passados,

Que dali nós partíramos, cortando

Os mares nunca de outrem navegados,

Prosperamente os ventos assoprando,

Quando uma noite, estando descuidados,

$\mathrm{Na}$ cortadora proa vigiando,

Uma nuvem que os ares escurece

Sobre nossas cabeças aparece (C.)

(PEREIRA, 1925, p. 350-351, maiúsculas e itálicos do autor/editor).

As "notas" e "observações", seções em que são fornecidas pelo autor "rápidas explanações históricas sobre a regra”, também são acrescidas de exemplos literários. Depois de explicar a regra dos pronomes oblíquos, segundo a qual "desses só os, a, os, as funcionam exclusivamente como objeto direto", Eduardo Carlos Pereira recorre a excertos de escritores portugueses, como Antonio Feliciano de Castilho (18001875) e Padre Antonio Vieira (1608-1697), para exemplificar o que considera um "brasileirismo", ou seja, o emprego dos pronomes retos em função de objeto direto:

Obs.

(...)

$2^{\mathrm{a}}$ É erro vulgar no Brasil dar ao caso reto dos pronomes substantivos funções objetivas, p. ex: Eu vi ELE, ele viu NÓS, chama EU, em vez de - eu O vi, ele NOS viu, chama-ME. Destes brasileirismos encontram-se, todavia, exemplos em clássicos portugueses: $E$ el-rei... degredou ELE e os filhos (Fern. Lopes apud. R. Barbosa). - Que em tal caso houvessem ELA por sua rainha e senhor (Id.) - Mas assi de 
Linha D'Água (Online), São Paulo, v. 29, n. 1, p. 119-141, jun. 2016

longe ordena ELES a ventura... (B. Ribeiro). TODO ELE aplicam (A. V.) - Eles falem por mim, ELES só ouve (A. de F.) (PEREIRA, 1925, p. 209-210, maiúsculas, itálicos e grifos do autor/editor).

Nos prólogos da $1^{\mathrm{a}}$ e $2^{\mathrm{a}}$ edições da Gramática expositiva: curso superior, publicados respectivamente em 1907 e 1909, Eduardo Carlos Pereira justifica o uso de "exemplos clássicos" como aqueles que "firmam a doutrina". Para o autor, "o abono das regras" deve se assentar, sobretudo, nos usos linguísticos de "modernos escritores de incontestável competência", principalmente nos usos dos autores do Romantismo português, Alexandre Herculano e Antonio Feliciano de Castilho, por considerá-los representativos da "língua viva de pessoas cultas". (cf. PEREIRA, Prólogo da 1a edição [1907], 1925, p. IV; Prólogo da 2a edição [1909], 1925)

Como foi mencionado anteriormente, a maioria dos escritores citados nos exemplos na é de nacionalidade portuguesa: na lista apresentada pelo autor, na abertura de sua obra, são dezessete os lusitanos, e apenas três os brasileiros. Para exemplificar os fenômenos atuais da língua, conforme justifica o próprio autor no prólogo, são citados trechos de autores modernos igualmente portugueses, como Alexandre Herculano e Antonio Feliciano de Castilho. E, ainda que usos do português do Brasil sejam tratados nas "notas" e "observações", é à língua literária de Portugal que Eduardo Carlos Pereira recorre na abonação dessas expressões brasileiras ${ }^{11}$. Se o discurso do exemplo nas gramáticas revela dados importantes sobre o uso/norma da língua e a modalidade escolhida como modelo, como aponta Leite (2001, p. 291), é possível dizer que, no livro escolar, privilegiou-se a variante europeia da língua portuguesa.

Embora, já no século XIX, a "questão da língua brasileira" tenha suscitado numerosos debates, polêmicas e estudos entre escritores e intelectuais brasileiros, que defendiam a existência de uma "expressão linguística brasileira" (cf. MARTINS, 1988, p. 9), a única polêmica em que Eduardo Carlos Pereira diz se apoiar

11 A pesquisa de Gurgel (2008) demonstra que, nas gramáticas publicadas entre os anos de 1880 e 1920, esta prática era comum. Ao investigar a questão da colocação pronominal nas obras de Mário Barreto (1879-1931), Alfredo Augusto Gomes (1859-1924), Maximino de Araújo Maciel (1865-1923), Manuel Pacheco Silva Junior (1842-1899) \& Lameira de Andrade (-), Eduardo Carlos Pereira (1 855-1923), Ernesto Carneiro Ribeiro (1839-1920), João Ribeiro (1860-1934), Júlio César Ribeiro (1845-1890) e Manuel Said Ali (1861-1953), a pesquisadora conclui que, no tratamento da questão, "apesar de ter havido algum esforço por alguns membros da geração brasileira de gramáticos em defender o 'meio' como princípio explicativo, as atenções não se voltaram à descrição da variante brasileira do português, haja vista expressiva presença de autores portugueses no exemplário" (GURGEL, 2008, p. 108). 
Linha D'Água (Online), São Paulo, v. 29, n. 1, p. 119-141, jun. 2016

é a em que estiveram envolvidos o senador Rui Barbosa (1849-1923) e seu antigo professor e gramático Ernesto Carneiro Ribeiro (1839-1920), a propósito da redação do Código Civil da República:

Cumpre-nos aqui confessar, agradecido, que, na pesquisa de exemplos clássicos, largo subsídio nos forneceu a luminosa polêmica, a qual, na redação do Código Civil, se travou entre dois agigantados cultores de nosso idioma, queremos falar do Dr. Rui Barbosa e do Dr. Ernesto Carneiro Ribeiro. Graças a esse manancial e ao esforço próprio, pudemos abonar amplamente a doutrina exposta com a citação de numerosos textos de escritores abalizados. (PEREIRA, Prólogo da $1^{\mathrm{a}}$ edição [1907], 1925, p. IV)

Ao analisar a documentação originada da prolongada discussão sobre a língua portuguesa, travada entre Rui Barbosa e Ernesto Carneiro Ribeiro, a qual recebeu os títulos de Réplica (Rui Barbosa, 1903) e Tréplica (Carneiro Ribeiro, 1905), Arruda (2010, p. 75 e 83) constatou que, apesar de os polemistas dizerem ser avessos ao purismo na linguagem, seus discursos revelaram, ao contrário, um apego à tradição; tanto que, para respaldar suas teses, ambos se apoiaram em numerosos exemplos extraídos de autores clássicos lusos, que, por sua vez, foram aproveitados por Pereira na elaboração da Gramática expositiva: curso superior, como o próprio autor revela no "Prólogo da 1a edição" (1907). De acordo com Ilari e Basso (2006, p. 240), na constituição da norma culta brasileira, a qual se estabeleceu entre os séculos XVIII e XX com base na norma culta lusitana, teve grande importância o papel dos gramáticos, que fixavam as regras amparando-se no uso que delas faziam os escritores portugueses.

Conforme salienta Faraco (2008, p. 107-108), durante o século XIX, a norma escrita brasileira buscou uma aproximação e identificação com o padrão lusitano, o qual tinha se firmado com o Romantismo português. Mais precisamente na década de 1880, quando se intensificou o processo de gramatização brasileira do português, com a publicação de inúmeras gramáticas, o esforço de definição das "estruturas corretas" da língua levou a um avanço significativo da lusitanização dessa norma escrita (FARACO, 2008, p. 124). A preservação da "pureza da linguagem", tendo como parâmetro o uso linguístico dos escritores lusitanos, interessava especialmente à elite brasileira conservadora, para quem a variante europeia do português representava uma superioridade cultural e um índice de civilização (FARACO, 2008, p. 109-111): 
Linha D'Água (Online), São Paulo, v. 29, n. 1, p. 119-141, jun. 2016

(...) a lusitanização progressiva da norma escrita, num período de 65 a 70 anos [1829 a 1891], se encaixa perfeitamente no projeto político da elite brasileira pós-independência de construir uma nação branca e europeizada, o que significava, entre outros muitos aspectos, distanciar-se e diferenciar-se do vulgo (para usar uma expressão comum nos textos dos intelectuais do século XIX), isto é, da população etnicamente mista e daquela de ascendência africana, que constituíam, sem dúvida, um estorvo grande àquele projeto (FARACO, 2008, p. 108).

Tendo em vista que o objetivo da escola secundária, no início do século XX, continuava sendo o de formar um pequeno grupo social, composto pelos filhos de famílias da oligarquia agrária, de industriais, grandes comerciantes, profissionais liberais ou da incipiente classe média urbana, a Gramática expositiva: curso superior, ao fixar uma norma padrão determinada pelo "bom uso" dos escritores portugueses, por meio da exemplificação, ao mesmo tempo em que estava em consonância com o modo como essa elite concebia a língua portuguesa, também atendia aos seus anseios, oferecendo-lhes as regras do "uso correto". Nesse sentido, a língua padrão abonada nos exemplos literários da obra de Eduardo Carlos Pereira, e ensinada nas aulas de português, constituía um sistema comunicativo que era associado a um patrimônio cultural, e, portanto a uma modalidade de prestígio, fixada na tradição escrita portuguesa; à qual, por sua vez, apenas uma parte reduzida da sociedade brasileira tinha acesso. (cf. GNERRE, 1991, p. 6)

A Gramática expositiva: curso superior, de Eduardo Carlos Pereira, ao utilizar excertos literários como exemplos das regras, retoma uma antiga tradição de estudos gramaticais surgida na Grécia Antiga, quando os gramáticos alexandrinos, realizando trabalhos de exegese e fixação dos textos de Homero, acabaram também por fixar os usos linguísticos do poeta grego como modelo de "bom uso" da língua. Essa relação entre literatura e gramática, que está na origem do surgimento da primeira gramática grega, chega até a Roma Antiga, influenciando a elaboração de gramáticas latinas, que passam a incluir, em sua estrutura, exemplos extraídos de escritores clássicos, como Cícero, Virgílio e Horácio, entre outros. Dessa herança também participam as gramáticas tradicionais brasileiras, como a Gramática expositiva: curso superior, na medida em que recorrem aos escritores de língua vernácula, para ilustrar um uso autorizado ou elucidar um preceito. A presença expressiva de escritores de nacionalidade portuguesa nos exemplos da obra de Eduardo Carlos Pereira revela, entretanto, que o gramático elegeu a variante europeia da língua portuguesa como "uso correto" do português; colaborando no estabelecimento de uma norma culta brasileira baseada na norma culta lusitana. 
Linha D'Água (Online), São Paulo, v. 29, n. 1, p. 119-141, jun. 2016

\section{Considerações finais}

Durante a Primeira República (1889 a 1930), a disciplina escolar Português ocupou um lugar expressivo nos currículos do ensino secundário. Isso devido à obrigatoriedade de Português nos exames preparatórios, e à valorização na escola das disciplinas de conteúdos de referência nacional, em virtude do nacionalismo da época. A gramática teve primazia, em relação à leitura e escrita de textos, no ensino de língua portuguesa ministrado nesse período; conforme indicam os planos de ensino elaborados pelo Colégio Pedro II, o elevado número de gramáticas adotadas no estabelecimento escolar, e a edição e reedição de inúmeras gramáticas brasileiras, nas duas últimas décadas do século XIX e três primeiras décadas do século XX.

A Gramática expositiva: curso superior, de Eduardo Carlos Pereira, livro escolar destinado ao aprendizado da gramática no $2^{\circ}$ e $3^{\circ}$ ano ginasial do secundário, teve largo alcance nas escolas secundárias e, por isso, pode ser representativa do ensino de gramática realizado na Primeira República. Embora a gramática escolar analisada faça uso da gramática histórica em suas descrições, na tentativa de conciliar o "tradicional" e o "moderno", ela termina por eleger como objeto de ensino a gramática normativa. $\mathrm{Na}$ prescrição das regras, o gramático toma por "correto" o uso linguístico dos escritores portugueses, principalmente aqueles pertencentes ao Romantismo português. Ao exemplificar as regras do que considera "bom uso" da língua portuguesa com excertos literários extraídos de escritores lusitanos, Eduardo Carlos Pereira retoma uma antiga tradição surgida ainda na Antiguidade clássica, que não estabelecia fronteiras precisas entre literatura e gramática, e colabora no estabelecimento de uma norma culta brasileira baseada na norma culta lusitana. Outros elementos da tradição ocidental de estudos gramaticais também são percebidos na Gramática expositiva: curso superior, como a organização de seus conteúdos em duas partes (lexeologia e sintaxe) e o tratamento dado a alguns conceitos (língua, linguagem, divisão das classes de palavras, frase e proposição), os quais já estavam presentes na Arte da gramática (I-II a. C.), de Dionísio Trácio, em Da sintaxe (II d. C.), de Apolônio Díscolo, em Institutiones grammaticae (V d. C.), de Prisciano.

\section{Referências}

ARRUDA, Mariléa Giacomini. A polêmica gramatical entre Rui Barbosa e Ernesto Carneiro Ribeiro sobre a redação do Projeto do Código Civil. Dissertação de Mestrado. Pontifícia Universidade Católica de São Paulo, 2010. 
Linha D'Água (Online), São Paulo, v. 29, n. 1, p. 119-141, jun. 2016

AZEVEDO, Fernando de. A cultura brasileira. São Paulo: Edusp, 2010.

BARATIN, Marc et al. Le livre 17 de l'Ars Prisciani. In: PRISCIEN. Grammaire: livre XVII - sintaxe, 1. Tradução francesa, introdução e notas de Marc Baratin et all. Paris: Librairie Philosophique J. Vrin, 2010.

BITTENCOURT, Circe Maria Fernandes. Autores de compêndios e livros de leitura (18101910). Educação e Pesquisa, São Paulo, v. 30, n. 3, p. 475-491, set./dez. 2004.

CURTIUS, Ernest Robert. Literatura europeia e Idade Média latina. Tradução de Teodoro Cabral e Paulo Rónai. São Paulo: Edusp, 2013.

ELIA, Sílvio. Os estudos filológicos no Brasil. In: Ensaios de filologia e linguística. $2^{\mathrm{a}}$ ed. Refundida e aumentada. Rio de Janeiro; Brasília: Grifo; INL, 1975.

FACCINA, Rosemeire Leão da Silva \& CASAGRANDE, Nancy dos Santos. A Gramática Expositiva da Língua Portuguesa: uma abordagem historiográfica. In: BASTOS, Neusa Barbosa \& PALMA Dieli Vesaro (orgs.). História entrelaçada 2: a construção de gramáticas e o ensino de lingua portuguesa na primeira metade do século XX. Rio de Janeiro: Lucerna, 2006.

FARACO, Carlos Alberto. Norma culta brasileira: desatando alguns nós. São Paulo: Parábola Editorial, 2008.

FÁVERO, Leonor Lopes \& MOLINA, Márcia Antonia Guedes. As concep̣ôes linguísticas no século XIX: a gramática no Brasil. Rio de Janeiro: Lucerna, 2006.

GNERRE, Maurizzio. Linguagem, escrita e poder. São Paulo: Martins Fontes, 1991.

GURGEL, Silvana. O periodo dos estudos linguísticos brasileiros dito cientifico na questão da colocafão pronominal (1880-1920). Dissertação de Mestrado. Faculdade de Filosofia Letras e Ciências Humanas, Universidade de São Paulo, 2008.

HANSEN, João Adolfo. Autor. In: JOBIM, José Luis (org.). Palavras da crítica. Rio de Janeiro: Imago, 1992.

ILARI, Rodolfo \& BASSO, Renato. O português da gente: a lingua que estudamos a lingua que falamos. São Paulo: Contexto: 2006.

LEITE, Marli Quadros. O discurso dos exemplos nas gramáticas portuguesas do século XVI. In: URBANO, Hudinilson et al. (orgs.). Dino Preti e seus temas: oralidade, literatura, midia e ensino. São Paulo: Cortez, 2001. 
Linha D'Água (Online), São Paulo, v. 29, n. 1, p. 119-141, jun. 2016

LEITE, Marli Quadros. Metalinguagem e discurso: a configuração do purismo brasileiro. São Paulo: Humanitas, 1999.

LEITE, Marli Quadros. O nascimento da gramática portuguesa: uso e norma. São Paulo: Paulistana; Humanitas FFLCH/USP, 2007.

LYONS, John. Introdução à linguística teórica. Tradução de Rosa Virgínia Mattos e Silva e Hélio Pimentel. São Paulo: Editora Nacional; Edusp, 1979.

MARTINS, Nilce Sant'Anna. História da lingua portuguesa V: século XIX. São Paulo: Ática, 1988.

MATTOS e SILVA, Rosa Virgínia. Tradição gramatical e gramática tradicional. São Paulo, Contexto, 1989.

MOLINA, Márcia Antonia Guedes. Um estudo descritivo-analitico da "Gramática expositiva (curso superior)", de Eduardo Carlos Pereira. Tese de Doutorado. Faculdade de Filosofia Letras e Ciências Humanas, Universidade de São Paulo, 2004.

NEVES, Maria Helena de Moura. A gramática: história, teoria e análise, ensino. São Paulo: Editora UNESP, 2002.

PEREIRA, Eduardo Carlos. Gramática expositiva: curso superior. 17a edição. São Paulo: Companhia Gráfico-Editora Monteiro Lobato, 1925.

PFROMM NETTO, Samuel et al. O livro na educação. Rio de Janeiro: Primor/Instituto Nacional do Livro, 1974.

RAZZINI, Márcia de Paula Gregório. O espelho da nação: a "Antologia nacional" e o ensino de português e de literatura (1838-1971). Tese de Doutorado. Instituto de Estudos da Linguagem, Universidade Estadual de Campinas, 2000.

RAZZINI, Márcia de Paula Gregório. História da disciplina Português na escola secundária brasileira. Revista Tempos e Espaços em Educação, Sergipe, v. 4, jan./jun., p. 43-58, 2010.

RIBEIRO, Maria Luisa Santos. História da educação brasileira: a organização escolar. São Paulo: Cortez, 1992.

ROBINS, Robert Henry. Pequena história da linguística. Tradução de Luiz Martins Monteiro. Rio de Janeiro: Ao Livro Técnico, 1983.

SILVA, Tomaz Tadeu da. Documentos de Identidade: uma introdução às teorias do currículo. 3a ed. Belo Horizonte: Autêntica, 2015. 
Linha D'Água (Online), São Paulo, v. 29, n. 1, p. 119-141, jun. 2016

SOARES, Magda. Português na escola: história de uma disciplina curricular. In: BAGNO, Marcos (org.). Linguística da norma. São Paulo: Loyola, 2004.

SOUZA, Rosa Fátima de. História da organização do trabalho escolar e do currículo no século XX: (ensino primário e secundário no Brasil). São Paulo: Cortez, 2008.

WEEDWOOD, Barbara. História concisa da linguística. Tradução de Marcos Bagno. São Paulo: Parábola Editorial, 2002.

Recebido em 28/03/2016

Aprovado em 28/05/2016 